\section{Storability in Cold Temperatures Can Be Evaluated Based on Changes in Fruit Quality in Apple Genotypes Under Shelf Life Conditions}

\author{
Hiroshi Iwanami', Shigeki Moriya, Nobuhiro Kotoda, \\ Sae Takahashi, and Kazuyuki Abe \\ Apple Breeding and Physiology Research Team, National Institute of Fruit \\ Tree Science, Shimo-kuriyagawa, Morioka, 020-0123, Japan
}

Additional index words. Malus $\times$ domestica, storage, cultivar difference, firmness, titratable acidity, regression

\begin{abstract}
To compare changes in fruit quality during cold storage with those during shelf life conditions, flesh firmness and titratable acidity (TA) were measured during storage in 20 apple (Malus $\times$ domestica Borkh.) cultivars. Fruit of each cultivar were divided into two groups and stored in chambers controlled at $20 \pm 2{ }^{\circ} \mathrm{C}$ and $85 \pm 5 \%$ relative humidity (RH) (shelf life conditions) or $0.5 \pm 0.3{ }^{\circ} \mathrm{C}$ and $95 \pm 5 \%$ RH (cold storage). Five of the stored fruit were removed for measurements at 5- or 10-d intervals for $40 \mathrm{~d}$ and at 1-month intervals until 10 months after harvest at $20^{\circ} \mathrm{C}$ and $0.5^{\circ} \mathrm{C}$, respectively. Data for firmness and $\mathrm{TA}$ were subjected to a linear regression and a nonlinear regression, respectively. Moreover, to determine the advantages of $0.5^{\circ} \mathrm{C}$ storage over $20^{\circ} \mathrm{C}$ storage for retaining firmness and $\mathrm{TA}$, the effect of storage type on extending the storage period was introduced as a parameter. The estimate of the effect of storage type showed that firmness and TA could be retained 8.9 and 3.7 times, respectively, longer at $0.5{ }^{\circ} \mathrm{C}$ than $20{ }^{\circ} \mathrm{C}$, independently of the cultivar. Therefore, firmness and $\mathrm{TA}$ after cold storage could be predicted by the change in firmness and TA during shelf life conditions. Moreover, cultivar differences regarding quality change under cold storage could be determined in a short period after harvest because the cultivar differences under shelf life conditions were detected within 1 month after harvest.
\end{abstract}

Storage potential is generally evaluated by measuring fruit quality before and after storage. A cultivar with the smallest change in fruit quality between at harvest and after storage or a cultivar with acceptable levels of quality as evaluated by sensory analysis after storage was determined to have a good storage potential. Because apples can be stored and are marketed year-round, the evaluation of fruit quality requires a long time and a large amount of fruit because measurements should be made several times during storage. This means that it is difficult to evaluate the storage potential and select cultivars for their storage potential in apple breeding programs. For this reason, Iwanami et al. (2004) measured changes in fruit firmness during shelf life conditions at $20^{\circ} \mathrm{C}$ and proposed a regression parameter that could be used as an indicator of storage potential in breeding programs. Changes in fruit quality in shelf life conditions were rapid, and cultivar differences regarding the changes could be determined shortly after harvest. However, the differences among cultivars regarding the degradation of fruit quality in shelf life conditions were not assumed to be

Received for publication 29 Oct. 2007. Accepted for publication 8 Jan. 2008.

${ }^{1}$ To whom reprint requests should be addressed; e-mail hiwanami@affrc.go.jp objectives of this study were 1) to measure changes in firmness and acidity during storage at $0.5^{\circ} \mathrm{C}$ (cold storage) and $20^{\circ} \mathrm{C}$ (shelf life conditions), 2) to reveal cultivar differences regarding the changes, and 3) to determine whether evaluation and selection were possible for storage potential on the basis of the quality changes occurring in shelf life conditions in apple breeding situations.

\section{Materials and Methods}

Fruit materials and storage conditions. Twenty apple cultivars from an orchard at the Apple Research Station at the National Institute of Fruit Tree Science, Japan, were selected on the basis of diversity of the harvest date. Eighty-five fruit from each cultivar were picked randomly from a tree when most of the fruit was determined to be mature on the basis of ground color, texture, flavor, and starch staining from August to Nov. 2004 (Table 1). After weighing the fruit, five apples were immediately used for measurements of firmness and TA at harvest. The remaining fruit were divided into groups of 30 and 50 and stored in chambers controlled at $20 \pm 2{ }^{\circ} \mathrm{C}$ and $85 \pm 5 \%$ relative humidity $(\mathrm{RH})$ and at $0.5 \pm 0.3{ }^{\circ} \mathrm{C}$ and $95 \pm 5 \% \mathrm{RH}$, respectively. Five of the stored fruit were removed for the measurements of fruit weight, firmness, and TA from the chamber at $20{ }^{\circ} \mathrm{C}$ at $5,10,15,20,30$, and $40 \mathrm{~d}$ after harvest and from the chamber at $0.5{ }^{\circ} \mathrm{C}$ at 1-month intervals until 10 months after harvest. Fruit displaying rot were immediately removed from the chamber during storage and when more than half of the stored fruit displayed rot or internal browning, measurements for the cultivar were discontinued.

Measurements of firmness and titratable acidity. Flesh firmness was measured using a fruit pressure tester (FT327; McCormick Fruit Technology, WA) mounted on a drill press and fitted with an $11.1-\mathrm{mm}$ probe on the pared surfaces of the sunny and shady sides

Table 1. Starch index, firmness, and titratable acidity at harvest in 20 cultivars evaluated in this study.

\begin{tabular}{lcccc}
\hline Cultivar & $\begin{array}{c}\text { Harvest } \\
\text { date }\end{array}$ & $\begin{array}{c}\text { Starch } \\
\text { index }^{\mathrm{z}}\end{array}$ & $\begin{array}{c}\text { Firmness } \\
(\mathrm{N})\end{array}$ & $\begin{array}{c}\text { Titratable acidity } \\
(\mathrm{g} / 100 \mathrm{~mL})\end{array}$ \\
\hline $\begin{array}{l}\text { American Summer } \\
\text { Pearmain }\end{array}$ & 26 Aug. & 3.2 & 65.1 & 0.682 \\
Sansa & 9 Sept. & 1.0 & 53.4 & 0.358 \\
Akane & 15 Sept. & 0.7 & 59.0 & 0.665 \\
Tsugaru & 15 Sept. & 2.0 & 65.1 & 0.437 \\
McIntosh & 24 Sept. & 1.5 & 56.9 & 0.866 \\
Silken & 24 Sept. & 2.0 & 58.3 & 0.430 \\
Santaro & 30 Sept. & 0.6 & 61.4 & 0.504 \\
Hatsuaki & 30 Sept. & 0.0 & 48.8 & 0.582 \\
Redgold & 8 Oct. & 3.4 & 57.8 & 0.430 \\
Senshu & 8 Oct. & 0.7 & 52.2 & 0.408 \\
Kitaro & 14 Oct. & 0.8 & 61.0 & 0.432 \\
Jonathan & 14 Oct. & 1.3 & 57.9 & 0.827 \\
Starking Delicious & 14 Oct. & 2.1 & 55.0 & 0.291 \\
Jonagold & 21 Oct. & 1.4 & 58.4 & 0.509 \\
Golden Delicious & 21 Oct. & 2.3 & 57.0 & 0.620 \\
Kotaro & 28 Oct. & 1.5 & 60.0 & 0.346 \\
Shinano Gold & 28 Oct. & 1.4 & 53.1 & 0.497 \\
Orin & 4 Nov. & 2.3 & 65.5 & 0.324 \\
Fuji & 11 Nov. & 1.3 & 63.5 & 0.487 \\
Ralls Janet & 19 Nov. & 1.4 & 71.3 & 0.715 \\
\hline
\end{tabular}

${ }^{z}$ The starch index by iodine solution was rated from $0=0 \%$ staining to $5=100 \%$ staining. 
of each fruit. Three of the five fruit were used for the measurement of TA. Crude juice was extracted with a juicer (MJ-C68; National, Osaka, Japan) from each fruit, which had been peeled and cored. After filtration, $2 \mathrm{~mL}$ of the juice was titrated with an autotitrator (AUT-301; TOA Electronics, Tokyo) to $\mathrm{pH}$ 8.0 with $0.1 \mathrm{~N} \mathrm{NaOH}$. Titration results were calculated as malic acid (in grams) per 100 $\mathrm{mL}$ of sample juice.

Statistical analysis. Firmness measurements of individual fruit sampled were subjected to a linear regression as described by Iwanami et al. (2004) (Fig. 1A) expressed as

$$
y_{i j l m}=\beta_{0 i j}+\beta_{1 i j} \cdot x_{i j l m}+e_{i j l m}
$$

where $y_{i j l m}$ is the firmness measurement as the dependent variable of $m$ th fruit at $l$ th days of storage under $j$ th storage condition in ith cultivar, $\beta_{0 i j}$ is an intercept of $i$ th cultivar under $j$ th storage condition, $\beta_{1 i j}$ is a regression coefficient of $i$ th cultivar under $j$ th storage condition, which expresses the firmness reduction rate, $x_{i j l m}$ is the days of storage as the independent variable of mth fruit at $l$ th days of storage under $j$ th storage condition in $i$ th cultivar, and $e_{i j l m}$ is the residual of the regression line.

Measurements of TA were subjected to a nonlinear regression (Fig. 1B). The nonlinear regression model that was proposed by Johnston et al. (2001) was modified slightly to fit our data and was expressed as

regression coefficient of $i$ th cultivar at $0.5^{\circ} \mathrm{C}$, $k_{i}$ is the effect of a storage condition as a parameter that fits the regression line at $0.5{ }^{\circ} \mathrm{C}$ to that at $20{ }^{\circ} \mathrm{C}$ by extending the period of storage at $20^{\circ} \mathrm{C}$, and $a_{j}$ is a dummy variable for $j$ th storage condition: $a=1$ at $0.5^{\circ} \mathrm{C}(j=1)$ and $a=0$ at $20{ }^{\circ} \mathrm{C}(j=2)$.

The effect of cold storage on retaining TA was estimated in the same way using Eq. [2].

$$
\begin{aligned}
y_{i j l m}= & \beta_{2 i}-\left(1-a_{j}\right) \cdot\left(\beta_{2 i}-\beta_{3 i}\right) \cdot\left[1-\frac{1}{\left[1+\exp \left\{\beta_{4 i} \cdot k_{i} \cdot x_{i j l m}-5.2+\ln \left(2^{1 / 0.2}-1\right)\right\}\right]^{0.2}}\right] \\
& -a_{j} \cdot\left(\beta_{2 i}-\beta_{3 i}\right) \cdot\left[1-\frac{1}{\left[1+\exp \left\{\beta_{4 i} \cdot x_{i j l m}-5.2+\ln \left(2^{1 / 0.2}-1\right)\right\}\right]^{0.2}}\right]+e_{i j l m}
\end{aligned}
$$

where $\beta_{2 i}$ is a common initial TA asymptote of $i$ th cultivar for both storage conditions, $\beta_{3 i}$ is a final TA asymptote of $i$ th cultivar under $0.5^{\circ} \mathrm{C}$ storage, $\beta_{4 i}$ is the rate of change in the TA of $i$ th cultivar at $0.5^{\circ} \mathrm{C}$, and $k_{i}$ is the effect of a storage condition as a parameter that fits the regression curve at $0.5^{\circ} \mathrm{C}$ to that at $20^{\circ} \mathrm{C}$ by extending the period of storage at $20^{\circ} \mathrm{C}$.

Estimations of all the parameters were performed using the REG and NLIN procedures of SAS (SAS Institute, Cary, NC). To determine whether the effects of the storage condition $\left(k_{i}\right)$ were different $\left(k_{i} \neq k\right)$ or the same $\left(k_{i}=k\right)$ among cultivars, Eqs. [3] and [4] were compared with the models in which $k_{i}$ was substituted for $k$ in the equations on the basis of Akaike's information criterion

$$
y_{i j l m}=\beta_{2 i j}-\left(\beta_{2 i j}-\beta_{3 i j}\right) \cdot\left[1-\frac{1}{\left[1+\exp \left\{\beta_{4 i j} \cdot x_{i j l m}-5.2+\ln \left(2^{1 / 0.2}-1\right)\right\}\right]^{0.2}}\right]+e_{i j l m}
$$

where $y_{i j l m}$ is the measurement of TA as the dependent variable of $m$ th fruit at $l$ th days of storage under $j$ th storage condition in $i$ th cultivar, $\beta_{2 i j}$ is an initial TA asymptote as a parameter of $i$ th cultivar under $j$ th storage condition, $\beta_{3 i j}$ is a final TA asymptote as a parameter of $i$ th cultivar under $j$ th storage condition, $\beta_{4 i j}$ is the rate of change in TA as a parameter of $i$ th cultivar under $j$ th storage condition, $x_{i j l m}$ is the days of storage as the independent variable of $m$ th fruit at $l$ th days of storage under $j$ th storage condition in $i$ th cultivar, and $e_{i j l m}$ is the residual of the regression curve.

To estimate the degree to which cold storage retains firmness compared with that at shelf life temperature, we made a regression model that is expressed in the subsequent equation. A parameter that expressed the effect of storage conditions on extending the storage period was introduced, and the linear regressions for a reduction in firmness under each condition were combined to consider the magnitude of the estimation error for all cultivars.

$$
\begin{aligned}
y_{i j l m}= & \beta_{0 i}+\left(1-a_{j}\right) \cdot \beta_{1 i} \cdot k_{i} \cdot x_{i j l m} \\
& +a_{j} \cdot \beta_{1 i} \cdot x_{i j l m}+e_{i j l m}
\end{aligned}
$$

where $\beta_{0 i}$ is a common intercept of $i$ th cultivar for both storage conditions, $\beta_{1 i}$ is a
(AIC). AIC can lead to an adequate regression model by comparing the number of parameters with the magnitude of the error in the model. The model with the smaller AIC is better.

\section{Results}

Weight loss of fruit continued to the end of the storage periods. The daily weight loss was correlated between 20 and $0.5^{\circ} \mathrm{C}$ storage among cultivars tested and was approximately seven times greater for the former than for the latter (data not shown).

Most cultivars lost firmness rapidly at $20{ }^{\circ} \mathrm{C}$ (Fig. 2), but no difference occurred for 'Senshu', 'Kitaro', 'Shinano Gold', and 'Fuji'. Softening at $0.5^{\circ} \mathrm{C}$ was slower than at $20{ }^{\circ} \mathrm{C}$. The softening slowed during storage, and firmness seldom changed until the end of storage under either condition in most cultivars. The fruit of 'American Summer Pearmain' and 'Silken' showed severe breakdown of the flesh after $20 \mathrm{~d}$ on the shelf, and no slow phase in the decrease of firmness was observed. The values of minimum firmness during storage differed among cultivars. The values of minimum firmness, however, were nearly identical under the two storage conditions in cultivars in which the decrease in firmness slowed during both storage condi- tions. Firmness at $20 \mathrm{~d}$ of storage at $20^{\circ} \mathrm{C}$ did not significantly differ from that at $180 \mathrm{~d}$ of storage at $0.5{ }^{\circ} \mathrm{C}$ in those cultivars. This means that the minimum firmness is not influenced by the storage conditions and depends on the cultivar.

To evaluate the differences in the decrease of firmness between at 20 and $0.5^{\circ} \mathrm{C}$, a linear regression was applied to the change in

firmness and parameters of the regression equation was compared. Because firmness did not always decease uniformly throughout the storage periods, the linear regression was adapted from the harvest date until firmness decreased just below $20 \%$ of harvest firmness (Fig. 1A). When firmness did not decrease more than $20 \%$ within $20 \mathrm{~d}$ at $20^{\circ} \mathrm{C}$ or within $150 \mathrm{~d}$ at $0.5{ }^{\circ} \mathrm{C}$, the regression lines were calculated using data from the harvest date until $20 \mathrm{~d}$ and $150 \mathrm{~d}$ at 20 and $0.5{ }^{\circ} \mathrm{C}$, respectively. On the other hand, although each parameter is estimated with error, the magnitude of the estimation error is entirely ignored if the parameter is compared and analyzed using analysis of variance or correlation between the two storage conditions. To compare the parameters, it is better to consider the magnitude of the estimation error. Therefore, Eq. [3] was constructed to calculate the magnitude of the estimation error, estimated parameters, and compared models.

The estimates of the effect of the storage condition $\left(k_{i}\right)$ in firmness changes widely varied among cultivars, from 4.7 to 16.8 (Table 2). Because the firmness of 'Senshu', 'Kitaro', 'Shinano Gold', and 'Fuji' did not decrease at $20{ }^{\circ} \mathrm{C}$, the four cultivars were excluded for the estimation. 'Tsugaru' had the least difference in the firmness reduction rate under either condition and 'Kotaro' had the largest. This means that the reduction rate in the firmness of 'Tsugaru' is 4.7 times and that of 'Kotaro' is 16.8 times slower at $0.5^{\circ} \mathrm{C}$ than at $20^{\circ} \mathrm{C}$. However, a comparison of a model in which the effect of storage conditions differed among cultivars with one in which the outcome was identical indicated that the latter was better on the basis of AIC and that the effect of storage conditions produced the same value $(8.9 \pm 0.5)$ among cultivars (Table 2). This means that the reduction rate in firmness was 8.9 times slower at $0.5{ }^{\circ} \mathrm{C}$ than $20{ }^{\circ} \mathrm{C}$ independently of the cultivar. When the number of days at $20{ }^{\circ} \mathrm{C}$ is multiplied by 8.9 , the regression lines of firmness change in both conditions fit well overall (Fig. 2).

Fruit of the four cultivars, 'Senshu', 'Kitaro', 'Shinano Gold', and 'Fuji', in which firmness did not decrease at $20^{\circ} \mathrm{C}$, softened at $0.5{ }^{\circ} \mathrm{C}$, and firmness reduction rates of those cultivars at $0.5^{\circ} \mathrm{C}$ were $0.08,0.05,0.06$, and $0.05 \mathrm{~N} \cdot \mathrm{d}^{-1}$, respectively. The firmness 

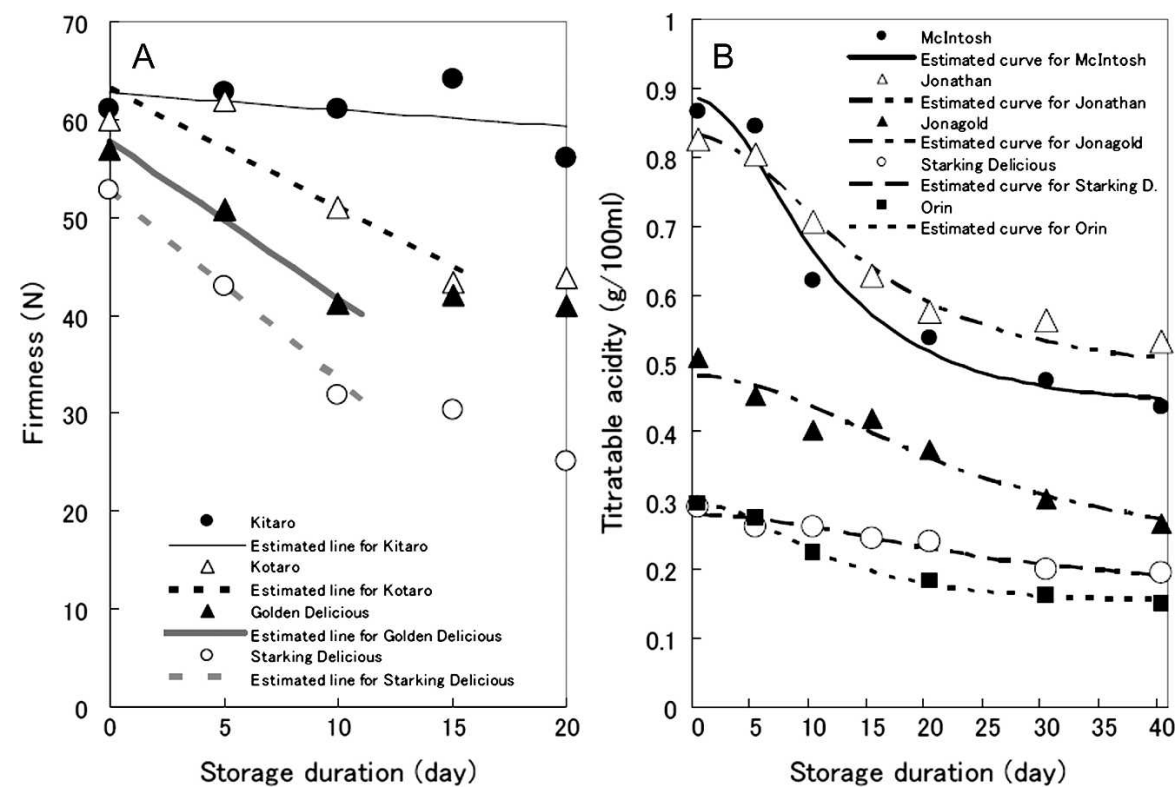

Fig. 1. Cultivar differences regarding change in (A) firmness and (B) titratable acidity under shelf life conditions $\left(20{ }^{\circ} \mathrm{C}, 85 \%\right.$ relative humidity) in apple and applications of regression Eqs. [1] and [2], respectively, to the changes.

reduction rates were small in comparison with softening rates of the other cultivars tested in our study, which were all higher than $0.1 \mathrm{~N} \cdot \mathrm{d}^{-1}$, except for 'Kotaro' $(0.07$ $\mathrm{N} \cdot \mathrm{d}^{-1}$ ) (data not shown).

The TA of all cultivars decreased rapidly after harvest under both storage conditions (Fig. 3). The decrease in TA became slow after a rapid reduction during storage, especially at $20{ }^{\circ} \mathrm{C}$, showing a typical sigmoid curve (Fig. 1B). Although the decrease in TA was slower at $0.5^{\circ} \mathrm{C}$ than $20^{\circ} \mathrm{C}$, the values of the minimum TA during storage were smaller at $0.5^{\circ} \mathrm{C}$ than $20{ }^{\circ} \mathrm{C}$.

To estimate the differences in the decrease of TA between at 20 and $0.5{ }^{\circ} \mathrm{C}$, a nonlinear regression was applied to the change in TA, and parameters of the regression equation were compared in the same way as the change in firmness. The degree of the decrease in TA was larger at $0.5^{\circ} \mathrm{C}$ than at $20{ }^{\circ} \mathrm{C}$, and the estimates of the final TA asymptote were largely different between both storage conditions, which resulted in misfits of both regression curves after an adjustment using the data of full-term storage. Therefore, data for $120 \mathrm{~d}$ were used for the estimation in storage at $0.5^{\circ} \mathrm{C}$.

The estimates of the effect of the storage condition $\left(k_{i}\right)$ in TA changes under both storage conditions also varied widely among cultivars, from 1.4 to 7.2 (Table 2). The reduction rate in TA of 'Kotaro' was 1.4 times and that of 'McIntosh' was 7.2 times slower at $0.5{ }^{\circ} \mathrm{C}$ than at $20{ }^{\circ} \mathrm{C}$. However, a comparison of a model with effects that differed among cultivars with one with identical effects indicated that the latter was better on the basis of AIC and the effect produced the same value $(3.7 \pm 0.2)$ among cultivars (Table 2). This means that the loss of TA was 3.7 times slower at $0.5^{\circ} \mathrm{C}$ than at $20{ }^{\circ} \mathrm{C}$ independently of the cultivar. When the days of storage at $20^{\circ} \mathrm{C}$ were multiplied by 3.7 , the regression curves of the TA change under both storage conditions fit well (Fig. 3).

\section{Discussion}

Fruit of four cultivars ('Senshu', 'Kitaro', 'Shinano Gold', and 'Fuji') did not soften at $20{ }^{\circ} \mathrm{C}$ (Fig. 2). Johnston et al. $(2001,2002 \mathrm{a})$ also observed that fruit softened slowly or increased in firmness when stored at $20^{\circ} \mathrm{C}$ in 'Granny Smith' and 'Pacific Rose', although fruit of both cultivars softened rapidly during storage at $0.5^{\circ} \mathrm{C}$. They concluded that a cold treatment was necessary for these cultivars to stimulate autocatalytic ethylene production and subsequent rapid softening at ambient temperatures. However, rates of firmness change during storage at $0{ }^{\circ} \mathrm{C}$ for 'Granny Smith' and 'Pacific Rose' were slower than those for the other cultivars tested in the study by Johnston et al. (2001). In our study, fruit of the four cultivars in which firmness did not decrease at $20^{\circ} \mathrm{C}$ softened more slowly than those of the other cultivars under storage at $0.5{ }^{\circ} \mathrm{C}$. Therefore, it is useful for apple breeders to measure changes in firmness after harvest under shelf life conditions for selecting a cultivar in which firmness decreases slowly under cold storage.

Excluding these four cultivars, firmness was retained 8.9 times longer under cold storage than shelf life conditions independently of the cultivar (Table 2; Fig. 2). We chose various types of cultivars for this study, including ones in which mealiness could develop during storage. 'American Summer Pearmain', 'Sansa', 'McIntosh', 'Silken', 'Redgold', 'Jonagold', and 'Starking Delicious' were reported to be cultivars in which mealiness developed and firmness decreased rapidly during storage at $20{ }^{\circ} \mathrm{C}$ (Iwanami et al., 2005b). Therefore, firmness after cold storage is predictable based on changes in firmness under shelf life conditions regardless of occurrence of mealiness when some harvest fruit were stored under shelf life conditions and measurements of the firmness were made at 5- or 10-d intervals during storage until 20 to $30 \mathrm{~d}$ after harvest. Several studies have attempted to predict firmness after storage using regression equations (Blankenship et al., 1997; Evensen et al., 1993; Ingle et al., 2000; Johnson and Ridout, 1998). The regression equations, however, required the measurement of several fruit characteristics at harvest, and the coefficient of determination was not always high. Ingle and Morris (1989) observed a significant correlation between the firmness change at 20 and $0{ }^{\circ} \mathrm{C}$ in 'Rome' apples harvested from 10 orchards in 2 years and proposed equations to predict the softening rate at $0{ }^{\circ} \mathrm{C}$ using the firmness at harvest and softening rate at $20{ }^{\circ} \mathrm{C}$ as parameters. However, they suggested that the procedure developed for 'Rome' to predict softening could not be applied to 'Delicious'.

Loss of TA was 3.7 times slower at $0.5^{\circ} \mathrm{C}$ than $20{ }^{\circ} \mathrm{C}$ independently of the cultivar (Table 2; Fig. 3). The estimate of the effect of storage conditions in TA was less than one-half of that in firmness. Moreover, the minimum TA during storage was smaller at $0.5^{\circ} \mathrm{C}$ than at $20{ }^{\circ} \mathrm{C}$ in most cultivars. These results indicated that cold temperatures do not suppress a reduction in TA postharvest as efficiently as they suppress softening. The decrease in TA could be a critical factor of unacceptable change in quality in a cultivar in which a decrease in firmness occurs slowly under cold storage. A decrease in firmness of 'Fuji' occurred slowly under cold storage, and the effect of a controlled atmosphere (CA) or 1-methylcyclopropene treatment on suppressing softening was nonexistent or only slight (Drake, 1993; Fan et al., 1999). However, CA storage is recommended for providing a good-quality apple even after short-term storage to suppress the TA reduction in 'Fuji' (Drake, 1993), although acceptable firmness could be retained under cold storage in this cultivar.

TA after cold storage can also be predicted based on changes in TA under shelf life conditions. The prediction of TA after cold storage by regression equations was reported in 'Starkspur Golden Delicious' (Fallahi et al., 1985). The regression equations also required measurements of mineral contents in leaves and fruit.

The nonlinear regression model, which was applied for the change in TA in this study, was originally proposed for the change in firmness during storage by Johnston et al. (2001). However, the model requires a phase change from a slow reduction at first to a rapid reduction later to fit the model to changes in measurement during storage, and they could not fit the model to the curves for the firmness reduction of some cultivars in which firmness decreased gradually. Moreover, because the model also requires a phase 

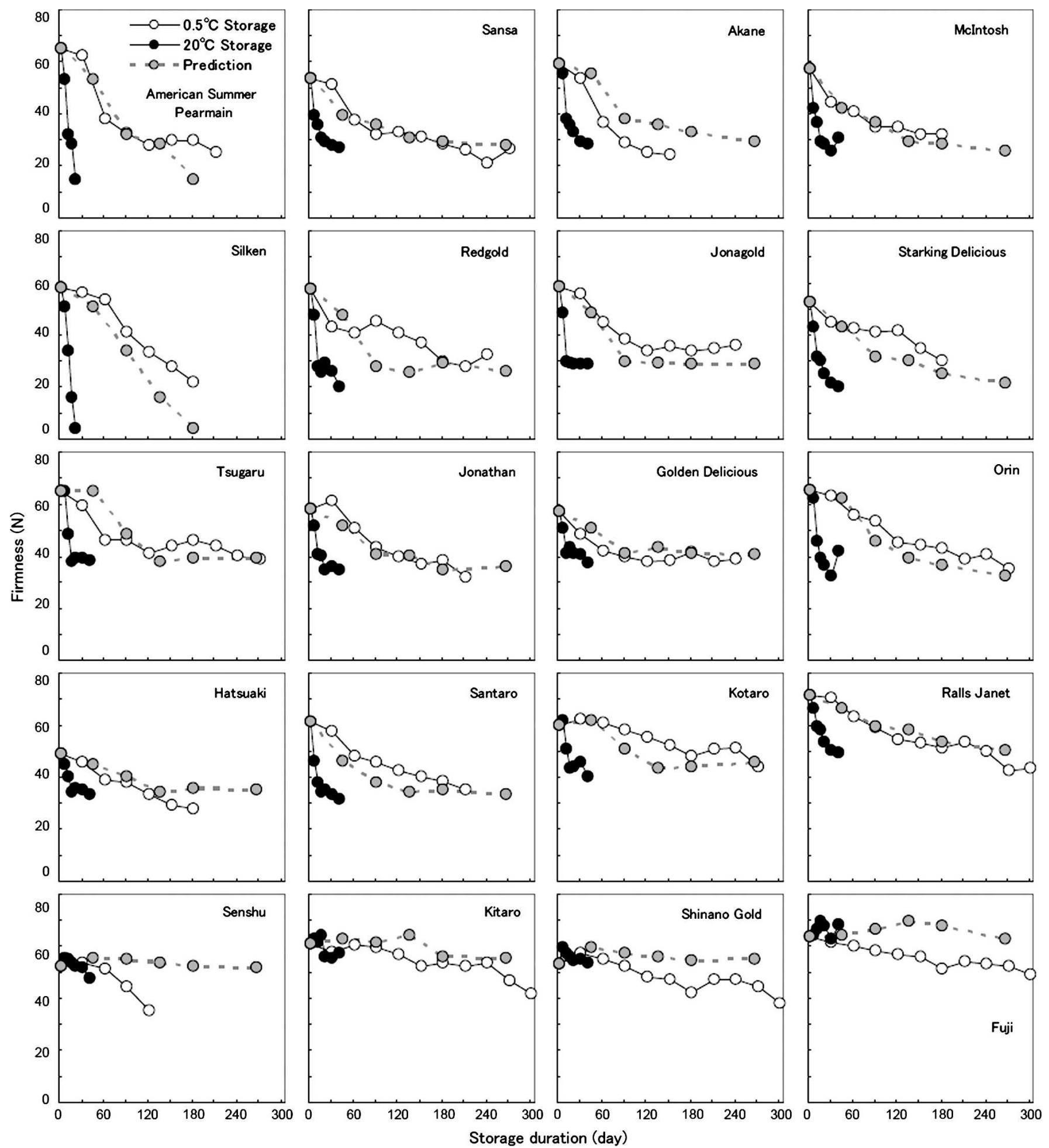

Fig. 2. Changes in firmness during storage at 20 and $0.5{ }^{\circ} \mathrm{C}$, and prediction of the changes at $0.5{ }^{\circ} \mathrm{C}$ based on the changes at $20{ }^{\circ} \mathrm{C}$ in 20 apple cultivars. The prediction was made by multiplying the days of storage at $20^{\circ} \mathrm{C}$ by 8.9 in each cultivar.

change from the rapid to a final slow reduction, the changes in firmness of 'American Summer Pearmain' and 'Silken' at $20^{\circ} \mathrm{C}$, in which softening continued, were not fitted by the model. Therefore, we did not apply the nonlinear regression model to the change in firmness and applied the linear model to the reduction period in firmness. Although the simple linear model was applied, the curves for the firmness change under both storage conditions fitted well overall (Fig. 2). On the other hand, changes in TA, which differ greatly among cultivars, were described well by the nonlinear regression model (Fig. 1B).

Because the degree of the change in firmness during storage can fluctuate depending on environmental factors such as harvest year (Ingle and Morris, 1989), orchard, and harvest date (Johnston et al., 2002b), the prediction of fruit quality after cold storage may not be accurate if each fruit under cold and shelf temperature is sampled under different environmental conditions. However, environmental variances of the firmness reduction rate such as those associated with genotype $\times$ year, year $\times$ tree, tree and harvest date were all reported to be very small by comparison with variance associated with genotype (Iwanami et al., 2005a). Therefore, the estimate of the effect of the storage 
Table 2. Comparison of the regression model, in which the response to storage conditions varies among cultivars $(\mathrm{ki} \neq \mathrm{k})$ with the model in which the response is the same $(\mathrm{ki}=\mathrm{k})$ using Akaike's information criterion (AIC) for the decrease in firmness and decrease in titratable acidity during storage.

\begin{tabular}{lcclr}
\hline Regression model & $\mathrm{n}$ & $\begin{array}{c}\text { Mean squares of } \\
\text { residual }\end{array}$ & $\begin{array}{l}\mathrm{k} \text { value (effect of } \\
\text { storage condition) }\end{array}$ & $\mathrm{AIC}$ \\
\hline Decrease in firmness & & & & \\
$\quad \mathrm{ki}=\mathrm{k}_{1} \approx \mathrm{k}_{16}$ in Eq. [3] & 478 & 287,547 & $\mathrm{ki}=4.7 \approx 16.8$ & $1,426.5$ \\
$\quad \mathrm{ki}=\mathrm{k}$ in Eq. [3] & 478 & 326,986 & $\mathrm{k}=8.9$ & $1,423.2$ \\
$\begin{array}{l}\text { Decrease in titratable acidity } \\
\quad \mathrm{ki}=\mathrm{k}_{1} \approx \mathrm{k}_{20} \text { in Eq. [4] }\end{array}$ & 701 & 1.2620 & $\mathrm{ki}=1.4 \approx 7.2$ & $-1,762.0$ \\
$\quad \mathrm{ki}=\mathrm{k}$ in Eq. [4] & 701 & 1.4275 & $\mathrm{k}=3.7$ & $-1,762.5$ \\
\hline
\end{tabular}

condition $(k)$ is reliable because genotypes with a wide range of softening rate were used for the estimation.

The most worthy result in this study is that the storage potential under cold storage can be evaluated from changes in quality under shelf life conditions. The change in fruit quality under shelf life conditions is rapid, and cultivar differences regarding quality change can be detected within 1 month of
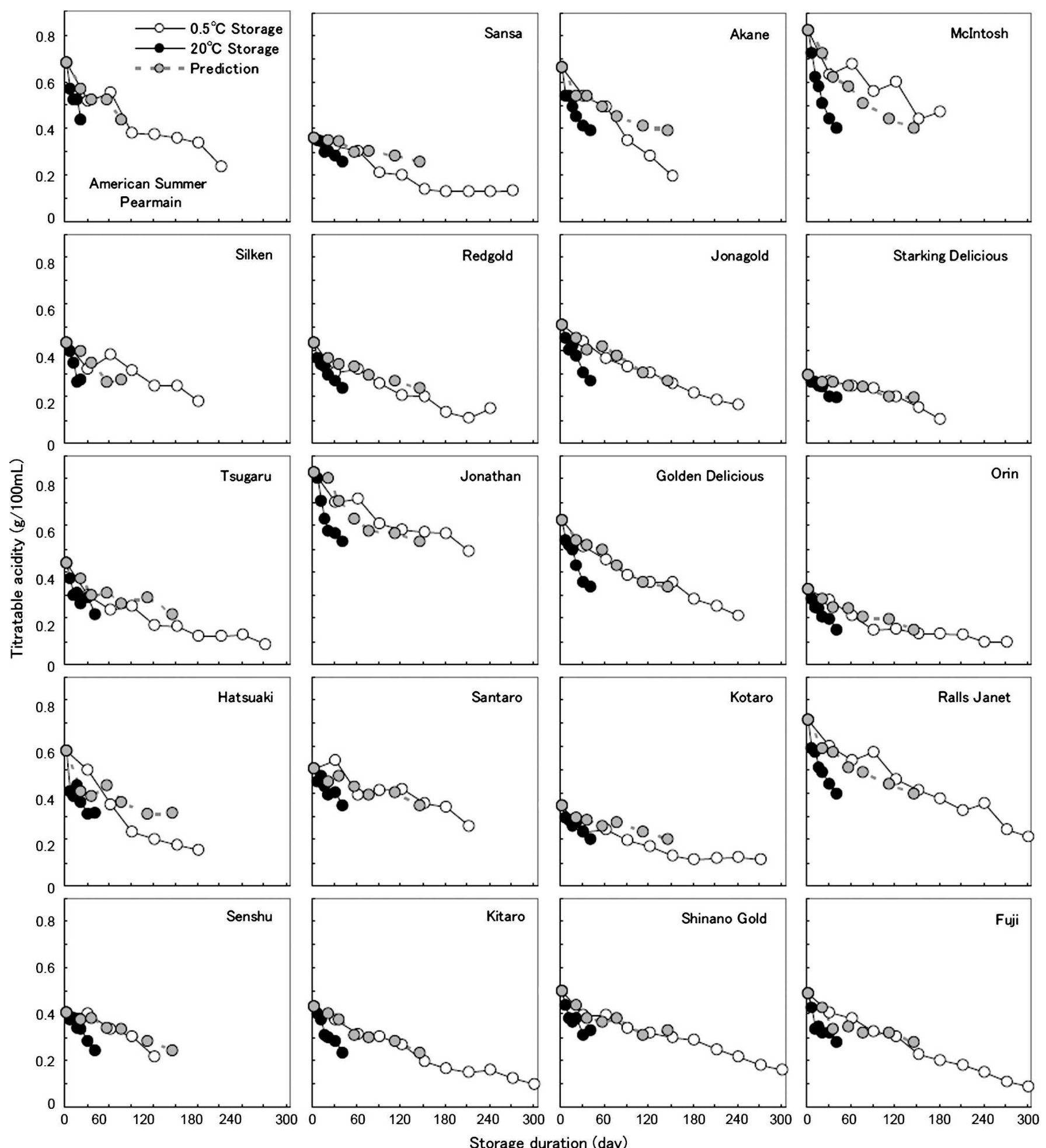

Fig. 3. Changes in titratable acidity during storage at 20 and $0.5^{\circ} \mathrm{C}$, and prediction of the changes at $0.5^{\circ} \mathrm{C}$ based on the changes at $20{ }^{\circ} \mathrm{C}$ in 20 apple cultivars. The prediction was made by multiplying the days of storage at $20^{\circ} \mathrm{C}$ by 3.7 in each cultivar. 
harvest. Because young seedlings do not produce enough fruit to permit extensive sampling for storage tests, seedling screening for storage potential is neglected in many breeding programs (Alston, 1988). In our study, storage potential could be evaluated from 35 fruit: five of each harvested fruit were used for the measurements of firmness and TA at 5-d intervals from harvest until $30 \mathrm{~d}$ postharvest. When the firmness of a cultivar does not significantly decrease under shelf life conditions, the cultivar is determined to have a hard fruit after cold storage, although the value of the firmness cannot be predicted.

Incidence of physiological disorders such as low-temperature breakdown, soft scald, and soggy breakdown, which are thought to be developed especially during cold storage, could also limit storage potential and some cultivars are reported to be susceptible to these disorders (Autio et al., 1986; Johnson and Ridout, 1998; Tong et al., 2003; Watkins et al., 2005). Therefore, it would be better to investigate the incidence of these disorders during cold storage if there are enough fruit for the long-term storage test.

In conclusion, most cultivars softened at both 0.5 and $20{ }^{\circ} \mathrm{C}$. 'Senshu', 'Kitaro', 'Shinano Gold', and 'Fuji' did not soften at $20{ }^{\circ} \mathrm{C}$, but did soften at $0.5^{\circ} \mathrm{C}$. Softening at $0.5{ }^{\circ} \mathrm{C}$ slowed after the initial softening phase. The TA of all cultivars decreased rapidly postharvest under both storage conditions. A comparison of a model in which the effect of storage condition on keeping quality was different among cultivars with one in which that was the same indicated that the latter was better on the basis of AIC and that the effect of storage condition produced the same values among cultivars for firmness change and TA change. Firmness and TA could be retained 8.9 and 3.7 times longer, respectively, at $0.5{ }^{\circ} \mathrm{C}$ than $20^{\circ} \mathrm{C}$, independently of the cultivar.

\section{Literature Cited}

Alston, F.H. 1988. Breeding apples for long storage. Acta Hort. 224:109-117.

Autio, W.R., W.J. Bramlage, and S.A. Weis. 1986. Predicting poststorage disorders of 'Cox's Orange Pippin' and 'Bramley's Seedling' apples by regression equations. J. Amer. Soc. Hort. Sci. 111:738-742.

Blankenship, S.M., M. Parker, and C.R. Unrath 1997. Use of maturity indices for predicting poststorage firmness of 'Fuji' apples. HortScience 32:909-910.

Drake, S.R. 1993. Short-term controlled atmosphere storage improved quality of several apple cultivars. J. Amer. Soc. Hort. Sci. 118:486-489.

Evensen, K., P. Hammer, R. Crassweller, G Greene, and L. Lehman-Salada. 1993. Predicting firmness of 'York Imperial' apples after long-term storage. HortTechnology 3:318 322 .

Fallahi, E., T.L. Righetti, and D.G. Richardson. 1985. Predictions of quality by preharvest fruit and leaf mineral analyses in 'Starkspur Golden Delicious' apple. J. Amer. Soc. Hort. Sci. 110:524-527.

Fan, X., S.M. Blankenship, and J.P. Mattheis. 1999. 1-Methylcyclopropene inhibits apple ripening. J. Amer. Soc. Hort. Sci. 124:690695.

Ingle, M., M.C. D'Souza, and E.C. Townsend. 2000. Fruit characteristics of 'York' apples during development and after storage. HortScience 35:95-98
Ingle, M. and J.C. Morris. 1989. Predicting firmness changes of 'Rome' apples in refrigerated storage. J. Amer. Soc. Hort. Sci. 114:90-94

Iwanami, H., M. Ishiguro, N. Kotoda, S. Takahashi, and J. Soejima. 2004. Evaluation of differences in softening of apple genotypes by linear regression. HortScience 39:1185-1188.

Iwanami, H., M. Ishiguro, N. Kotoda, S. Takahashi, and J. Soejima. 2005a. Optimal sampling strategies for evaluating fruit softening after harvest in apple breeding. Euphytica 144:169-175.

Iwanami, H., S. Moriya, N. Kotoda, S. Takahashi, and K. Abe. 2005b. Influence of mealiness on the firmness of apples after harvest. HortScience 40:2091-2095.

Johnson, D.S. and M.S. Ridout. 1998. Prediction of storage quality of 'Cox's Orange Pippin' apples from nutritional and meteorological data using multiple regression models selected by cross validation. J. Hort. Sci. Biotechnol. 73:622-630.

Johnston, J.W., E.W. Hewett, M.L.A.T.M. Hertog, and F.R. Harker. 2001. Temperature induces differential softening responses in apple cultivars. Postharvest Biol. Technol. 23:185-196.

Johnston, J.W., E.W. Hewett, M.L.A.T.M. Hertog, and F.R. Harker. 2002a. Temperature and ethylene affect induction of rapid softening in 'Granny Smith' and 'Pacific Rose' apple cultivars. Postharvest Biol. Technol. 25:257-264.

Johnston, J.W., E.W. Hewett, M.L.A.T.M. Hertog, and F.R. Harker. 2002b. Harvest date and fruit size affect postharvest softening of apple fruit. J. Hort. Sci. Biotechnol. 77:355-360.

Tong, C.B.S., D.S. Bedford, J.J. Luby, F.M Propsom, R.M. Beaudry, J.P. Mattheis, C.B Watkins, and S.A. Weis. 2003. Location and temperature effects on soft scald in 'Honeycrisp' apples. HortScience 38:1153-1155.

Watkins, C.B., M. Erkan, J.F. Nock, K.A. Iungerman, R.M. Beaudry, and R.E. Moran. 2005. Harvest date effects on maturity, quality, and storage disorders of 'Honeycrisp' apples. HortScience 40:164-169. 